\title{
Preliminary investigation of Nauclea latifolia ripe fruits for antioxidant and antidiabetic activities
}

\begin{abstract}
Akinwunmi Olubunmi Adenike*
Department of Chemistry, Faculty of Science, Ekiti State University, PMB 5363, Ado-Ekiti, Ekiti State, Nigeria

Olatunde Olalekan Christian

Department of Industrial Chemistry, Faculty of Science, Ekiti State University, PMB 5363, Ado-Ekiti, Ekiti State, Nigeria.

Adefemi Samuel

Department of Chemistry, Faculty of Science, Ekiti State University, PMB 5363, Ado-Ekiti,

Ekiti State, Nigeria

"Corresponding author: Email: nikxyglo@yahoo.com

Abstract

Fruits of Nauclea latifolia (Family Rubiaceae) have been used as food and medicinal plants. The ethnomedicinal reports indicated that it can be traditionally used for the treatment of dysentery, diarrhea, diabetes, malaria etc. The aim of this work was to evaluate the antioxidant, $\alpha$-amylase and $\alpha$-glucosidase activities of methanol extract of $N$. latifolia fruits at varying concentrations $(20-100 \mu \mathrm{g} / \mathrm{ml})$ using standard methods. The results of the $\mathrm{DPPH}$ and nitric oxide free radical scavenging capacity showed $\mathrm{IC}_{50}$ values $92.0 \mu \mathrm{g} / \mathrm{ml}$ and $30.0 \mu \mathrm{g} / \mathrm{ml}$ respectively indicating a good inhibitory capacity but lesser when compared to the standard, ascorbic acid which are $<10.0 \mu \mathrm{g} / \mathrm{ml}$ and $<20.0 \mu \mathrm{g} / \mathrm{ml}$ respectively. The analysis shows total phenolic contents of $147.9 \pm 3.35 \mathrm{mg} / \mathrm{g}$ and ferric reducing antioxidant potential of $1604.1 \pm 9.20 \mathrm{mg} / \mathrm{g}$ supporting the fact that phenolics are highly potent antioxidants. Based on the results obtained from $\alpha$-amylase and $\alpha$-glucosidase inhibition, the $I_{50}>100 \mu \mathrm{g} / \mathrm{ml}$ showing a lesser inhibitory activity when compared to the standard Acarbose with $I_{50}$ values of $50.1 \mu \mathrm{g} / \mathrm{ml}$ and $44.0 \mu \mathrm{g} / \mathrm{ml}$ respectively. The results clearly indicate that the methanol extract of $N$. latifolia has a moderate free radical scavenging activity resulting from various interaction between different components of the plant. It can be concluded that the fruits may provide natural source of bioactive compounds which is beneficial to human health and can be used as basis of folkloric remedies for diabetes.
\end{abstract}

Keywords: Amylase, Antioxidants, Diabetes, Glucosidase, Nauclea latifolia

\section{Article Info}

https://doi.org/

10.31018/jans.v11i3.2153

Received: July 29, 2019

Revised: September 5, 2019

Accepted: September 8, 2019

\section{How to Cite}

Adenike, A.O. et al. (2019). Preliminary investigation of Nauclea latifolia ripe fruits for antioxidant and antidiabetic activities. Journal of Applied and Natural Science, 11(3): 718- 723 https://doi.org/ 10.31018/jans.v11i3.2153

\section{INTRODUCTION}

Medicinal plants of tropical sub-Saharan Africa have been broadly used by indigenous people for traditional remedies. It also provides an important therapeutic option for a large part of the communities (Moyo et al., 2015, Haudecoeur et al., 2018). Chemically reactive species containing oxygen, such as hydroxyl radical, singlet oxygen, peroxides are produced as a natural by-product of the normal metabolism of oxygen. Free radicals, belonging to a group of reactive oxygen species, are produced through endogenous source (human body) and exogenous sources such as tobacco smoke, burning of fossil fuels and ozone. Some of their biological roles include: the regulation of normal metabolic process and immune function including cell growth, energy production and synthesis of nucleic acids, hormones and proteins (Sen et al., 2010). The imbalance between the produc- tion of reactive oxygen species and the activity of the antioxidant defenses is referred to as oxidative stress (Krovánová et al., 2012).

Oxidative stress has been known to pose serious health challenges whenever there is disparity between their production and the ability of the biological system to neutralize them (Hadi et al., 2007). The interest in natural antioxidants has significantly increased; currently, there has been global awareness towards the use and exploration of antioxidants from natural origin.. These biologically active compounds have been reported to neutralize free radicals or decompose formation of peroxides. Diabetes is an endocrinological disorder arising from insulin deficiency. The disease is caused by the inability of pancreas to produce insulin or inability of the body metabolic system to properly use the insulin produced. Diabetes is a predominant disease among the citizens of both developed and developing countries. The disease 
results in high urine production, thirst and blurred vision, lethargy and changes in energy metabolism (Patel et al., 2012).

The search for medicinal plants for the treatment of diabetes is on the increase since it could provide prospects for the development of novel agents for the treatment of the disease (Abdul et al., 2014).

Nauclea latifolia plant is from 'Rubiaceae'family. It is a shrub or small tree, native to tropical Africa. The plant is made of fruits, which has a lot of brownish seeds embedded within it and surrounded by a pink, edible andsweet-sour pulp. The fruits are usually red and fleshy when ripe, resembling hard strawberry and yellow when unripe (Iwu, 1993; Fadipe et al., 2015). The plant has been used locally in the treatment of malaria, hypertension, worm infestation, bacteria and virus infections, and as a purgative (Fadipe et al., 2015; Haudecoeur et al., 2018). In Nigeria, N. latifolia fruits are occasionally used in the treatment of piles and dysentery (Fadipe et al., 2015).

The purpose of the study was to assess the antioxidant and antidiabetic effect of ripe $N$. latifolia fruit extract. This study was prompted by the claim of some traditional health practitioners in the South-western part of Nigeria that the fruits of $N$. latifolia are effective remedies for the management and or control of diabetes.

\section{MATERIALS AND METHODS}

The ripe fruits of $N$. latifolia were collected from Ekiti State University, Ado-Ekiti, Ekiti State, Nigeria and was authenticated at the Department of Plant Science and Biotechnology. Folin-Ciocalteu reagent, iodine reagent, sodium nitroprusside, naphthylethylenediamine dihydrochloride, Griess reagent, 2,2-diphenyl-1-pcrylhydraxyl (DPPH), para-nitrophenylglucopyranoside, gallic acid and methanol were all supplied as analytical grade reagents and were used without any further purification.

Sample extraction: Disease free fruits were chopped into small pieces, sun dried for $3 \mathrm{~h}$ to reduce moisture content and later air-dried at room temperature for two weeks. The sample was ground into smaller particles using mortar and further pulverized using a mechanical grinder. About $1.5 \mathrm{~kg}$ of the crude plant was extracted with methanol for $24 \mathrm{~h}$, the mixture filtered and the filtrate was transferred into a rotatory evaporator and concentrated to dryness at $50{ }^{\circ} \mathrm{C}$ to obtain $44.5 \mathrm{~g}$ of the extract which was then stored in an air tight sample vial pending further analysis.

Evaluation of ferric reducing antioxidant potential (FRAP-Assay): The FRAP assay, which is based on the ability of antioxidants to reduce $\mathrm{Fe}^{3+}$ to $\mathrm{Fe}^{2+}$ in the presence of 2,4,6-tri(2-pyridyl) s-triazine (TPTZ) to form an intense blue $\mathrm{Fe}^{2+}$ TPTZ complex with an absorption maxima at 593 $\mathrm{nm}$. The reaction is $\mathrm{pH}$-dependent with an optimum $\mathrm{pH}$ of 3.6. The absorbance decrease is proportional to the antioxidant content (Benzie and Strain, 1996). In this assay, $0.2 \mathrm{ml}$ of the extract was added to $3.8 \mathrm{ml}$ of FRAP reagent prepared from the miture of $300 \mathrm{mM}$ sodium acetate buffer at $\mathrm{pH} 3.6,10.0 \mathrm{mM}$ TPTZ solution and $20.0 \mathrm{mM} \mathrm{FeCl}_{3}$. $6 \mathrm{H}_{2} \mathrm{O}$ solution. The reaction mixture was incubated at $37^{\circ} \mathrm{C}$ for $30 \mathrm{~min}$ and the absorbance increase at $593 \mathrm{~nm}$ was measured. Different concentrations of $\mathrm{FeSO}_{4}$ solution was used for calibration. The antioxidant capacity was calculated based on the ability of the plant samples to reduce ferric ions from the linear calibration curve and expressed as $\mathrm{mmol}^{\mathrm{FeSO}_{4}}$ equivalents per gram of sample. Ascorbic acid (Vitamin C) was used as a positive control.

Determination of total phenolic content (TPC): The total phenolic content of the methanol extract was determined using a adapted form of the Folin Ciocalteu reagent (FCR) method (Liu et al.,2006). $1 \mathrm{mg}$ of methanolic extract was dissolved in $10 \mathrm{ml}$ methanol (100ppm). 500 $\mu$ l (triplicates) were withdrawn into test tubes and $0.5 \mathrm{ml}$ of Folin Ciocalteu reagent together with $10 \mathrm{ml}$ of $7 \%$ sodium carbonate were added and vortex mixed. All the test tubes were wrapped with dark colored paper and the absorbance of the resulting blue color was measured at 765nm after $1 \mathrm{~h}$. Quantitative measurements were performed, based on a standard calibration curve of five points ranging from $0-40$ ppm of gallic acid in methanol. Methanol was used to prepare the blank, while the total phenolic content was expressed as gallic acid equivalents (GAE) in $\mathrm{mg} / \mathrm{g}$ crude extracts.

Determination of DPPH radical assay: This assay was carried using the method of Shirwaikar et al. (2006). This method depends on the reduction of purple DPPH to a yellow coloured diphenyl picrylhydrazine. The remaining DPPH with the maximum absorption at $517 \mathrm{~nm}$ was measured. About $2 \mathrm{ml}$ of various concentrations $(20-100 \mu \mathrm{g} / \mathrm{ml})$ of the extract were added to $2 \mathrm{ml}$ solution of $0.1 \mathrm{mM}$ DPPH. An equal amount of methanol and DPPH served as control, while the absorbance of the samples were measured after $20 \mathrm{~min}$ of incubation at $37{ }^{\circ} \mathrm{C}$ in the dark at $517 \mathrm{~nm}$. The DPPH radical scavenging activity was calculated according to the following equation:

$$
\% \text { inhibition }=\left[\frac{\text { Absorbance of blank-Absorbance of sample }}{\text { Absorbance of blank }}\right] \times 100
$$

Evaluation of nitric oxide scavenging activity: The nitric oxide generated from sodium nitroprusside in aqueous solution at physiological $\mathrm{pH}$ relate with oxygen to produce nitrite ions, which were measured using the Griess reaction reagent (Green et al., 1982).

About $3.0 \mathrm{ml}$ of $10 \mathrm{mM}$ sodium nitroprusside in phosphate buffer was added to $2.0 \mathrm{ml}$ of extract 
and reference compound in different concentrations $(20-100 \mu \mathrm{g} / \mathrm{ml})$. The subsequent solutions were then incubated at $25{ }^{\circ} \mathrm{C}$ for $1 \mathrm{hr}$. Methanol was used as blank in the reaction. To $5.0 \mathrm{ml}$ of the incubated sample, $5.0 \mathrm{ml}$ of Griess reagent containing $1 \%$ sulphanilamide and $0.1 \%$ naphthyethylene diamine dihydrochloride in $2 \%$ $\mathrm{H}_{3} \mathrm{PO}_{3}$ was added and absorbance of the chromophore formed was measured at $540 \mathrm{~nm}$. The percent inhibition of the nitrite oxide generated was determined by comparing the absorbance values of control and test preparations using equation 1 as above.

Determination of $\alpha$-glucosidase inhibition: The percent inhibitory effect of $N$. latifolia extracts on a -glucosidase activity was determined according to the chromogenic method described by Kim et al., 2005. About $20-100 \mu \mathrm{g} / \mathrm{ml}$ of the different concentrations of $N$. latifolia fruits extract were preincubated with 5 units of a-glucosidase for $15 \mathrm{~min}$, thereafter, $3 \mathrm{mM}$ Para nitrophenylglucopyranoside (PNPG) dissolved in $20 \mathrm{mM}$ phosphate buffer at $\mathrm{pH} 6.9$ was added to start the reaction. The reaction mixture was further incubated at $37^{\circ}$ $\mathrm{C}$ for $20 \mathrm{~min}$ and stopped by addition of $2 \mathrm{ml}$ of $0.1 \mathrm{M}$ sodium carbonate. The $\alpha$-glucosidase activity was determined by measuring the yellow colored p-nitrophenol released from PNPG at 400 $\mathrm{nm}$. The tests were done in triplicates and the mean absorption was used to calculate percentage $\alpha$-glucosidase inhibition which was calculated according to equation 1 .

Determination of $\alpha$-amylose inhibition: The percent inhibition of $\alpha$-amylase activity was conducted using the starch-iodine method reported by Xiao et al. (2006). The total assay mixture comprising $120 \mu \mathrm{l}$ of $0.02 \mathrm{M}$ sodium phosphate buffer (containing $6 \mathrm{mM}$ sodium chloride, $\mathrm{pH} 6.9$ ), $1.5 \mathrm{ml}$ of salivary amylase and plant extracts (20-100) $\mu \mathrm{g} / \mathrm{ml}$ were incubated at $37^{\circ} \mathrm{C}$ for $10 \mathrm{~min}$. $1 \%(\mathrm{w} /$ v) soluble starch was then added to each reaction mixture and were incubated at $37^{\circ} \mathrm{C}$ for $15 \mathrm{~min}$. $60 \mu \mathrm{l}$ of $1 \mathrm{M} \mathrm{HCl}$ was added to stop the enzymatic reaction, followed by the addition of $300 \mu$ l of iodine reagent ( $5 \mathrm{mM}$ each of $\mathrm{I}_{2}$ and $\mathrm{KI}$ ). The colour change was detected and the absorbance was measured at $620 \mathrm{~nm}$ while the percentage inhibition was calculated using equation 1 above.

\section{RESULTS AND DISCUSSION}

Antioxidant activity of N. latifolia fruit extract: Antioxidants can be described as compounds with the ability to delay autoxidation either via the inhibition of free radical formation or interruption of free radical propagation.. Their mode of action could be through one or more of many mechanisms which includes: scavenging of peroxidation initiating species, reduction of local $\mathrm{O}_{3}$ concentrations, halting the autoxidative chain reaction, quenching of radical species and metal ion chela-
Table 1. FRAP and TPC contents of methanol extract of $\mathrm{N}$. latifolia fruit (mean \pm SEM).

\begin{tabular}{ll}
\hline FRAP (AAE $\mathbf{~ m g / 1 0 0 g})$ & TPC (GAE $\mathbf{~ m g / 1 0 0 g ) ~}$ \\
$1604.1 \pm 9.20$ & $147.9 \pm 3.35$ \\
\hline
\end{tabular}

tion to prevent reactive specie generation or lipid decomposition (Brewer, 2011). The antioxidant activity of a specific antioxidant could be influenced by its hydro-/lipophilicity and structure (Koleva et al., 2002). The antioxidant activities of N. latifolia fruits extract was evaluated using DPPH radical scavenging assay, nitric oxide scavenging activity, total phenolic content and FRAP assays.

The ability of antioxidants to reduce ferric ion $\left(\mathrm{Fe}^{3+}\right)$ to ferrous ion $\left(\mathrm{Fe}^{2+}\right)$ due to the donation of hydrogen atom which interrupts the free radical chain was explored in the FRAP assay. The reduction reaction led to the formation of blue coloured ferrous tripyridyltriazine complex $\left(\mathrm{Fe}^{2+}\right.$ TPTZ), which is then determined spectrophotometrically by measuring absorption at $593 \mathrm{~nm}$ (Chung et al., 2002). The FRAP value for methanol extract of N. latifolia fruits (Table 1) expressed in terms of the Ascorbic acid equivalent was found to be $1604.1 \pm 9.20 \mathrm{AAE} \mathrm{mg} / 100 \mathrm{~g}$. The FRAP assay confirms the presence of compounds that donates electrons to free radicals, which terminate the free radical chain reaction by transforming them into more stable substances (Labiad et al., 2017). The N. latifolia fruits extract showed greater ferric reducing capability compared to hydroethanol, dichloromethane, ethyl acetate and hexane extracts of Thymus satureioides with FRAP values of 233.29, 153.45, 123.00 and $97.81 \mathrm{mg}$ equivalent of ascorbic acid/g of extract respectively (Labiad et al., 2017). When compared to FRAP analysis of aqueous extracts of $N$. latifolia, the methanol extract showed far greater activity (1604.1 mg AEE/100g $\approx 91.02 \mu \mathrm{mol} \mathrm{AEE/g)} \mathrm{com-}$ pared to $12.23 \mu \mathrm{mol}$ AEE/g (Ayeleso et al., 2014). This corroborated the assertion that methanol is highly efficient in the extraction of antioxidants from plant materials (Esmaeli et al., 2015).

The total phenol content of the fruit extract of $N$. latifolia was $147.9 \pm 3.35 \mathrm{GAE} \mathrm{mg} / 100 \mathrm{~g}$ expressed as gallic acid equivalent (Table 1). Phenolic compounds contributes to antioxidative activities due to their capacity to donate the hydrogen atoms from their hydroxyl groups, it is thus generally inferred that the antioxidative activity of a plant extract could be directly correlated to its phenol content (Mahdi-Pour et al., 2012). However, reports have emerged, that high phenolic content may not always result in high antioxidant activity (Agbor et al., 2005) This is seen in the case of DPPH scavenging activity of $N$. latifolia fruits extract, which is relatively low despite the high phenolic content of the extract. For polyphenols, their antioxidant ac- 


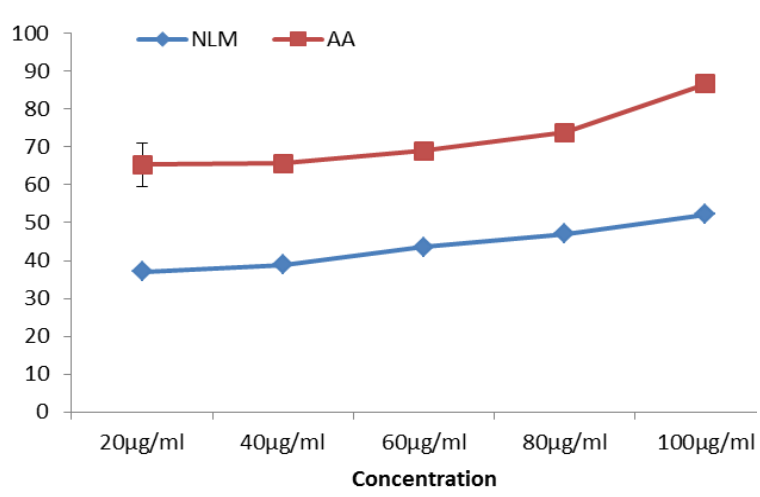

Fig. 1. DPPH scavenging activity of $N$. latifolia fruits (NLM) with Ascorbic acid (AA), (mean \pm SEM) of triplicates.

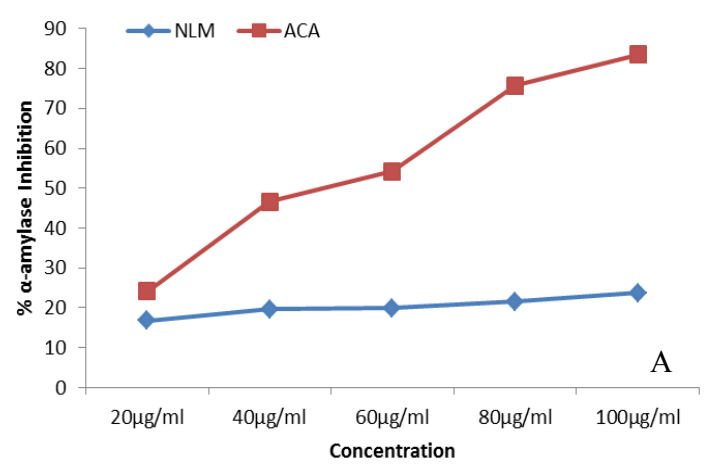

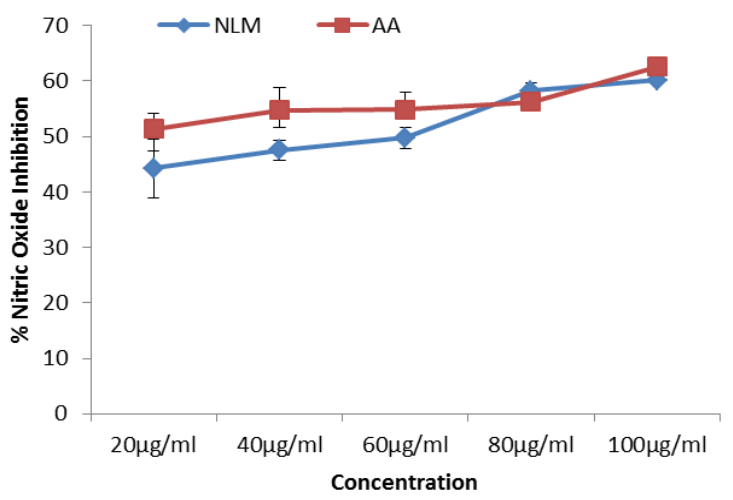

Fig. 2. Nitric oxide radical scavenging activities of $N$. latifolia fruits and Ascorbic acid (AA). Values are expressed as mean $\pm S E M, n=3$.

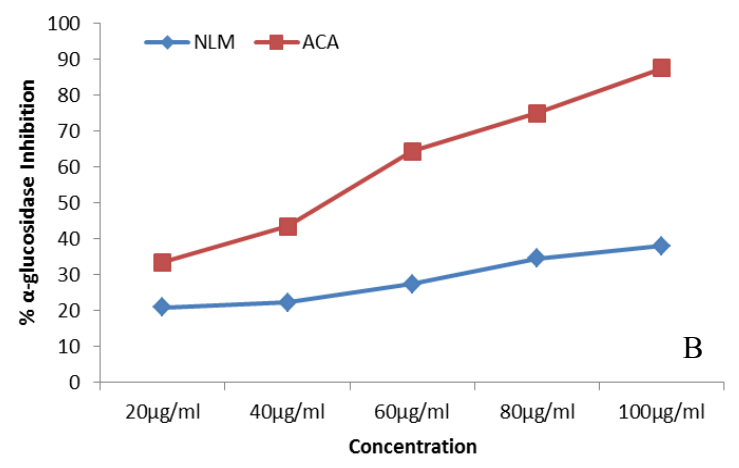

Fig. 3. Percentage inhibition of $\alpha$-amylase $(A)$ and $\alpha$-glucosidase (B) enzymes by methanolic extract of $\mathrm{N}$. latifolia fruits. Acarbose was used as the reference (values are expressed as mean $\pm S E M), n=3$.

tivity is greatly determined by their chemical structure and electron donation/reception capability, resulting in delocalized unpaired electrons in the aromatic structure (Saha and Verma, 2014).

The DPPH radical assay is usually employed in determining the ability of a compound to scavenge free radicals or act as hydrogen donor (Singh et al., 2012). The DPPH scavenging activity of an antioxidant is independent on the polarity of the compound but mainly dependent on the structure of the antioxidant. The $\mathrm{IC}_{50}$ value was found to be $92.0 \mu \mathrm{g} / \mathrm{ml}$, while that of Ascorbic acid (standard) was $<10.0 \mu \mathrm{g} / \mathrm{ml}$ (Fig. 1). Though the lower the $\mathrm{IC}_{50}$ value the better the antioxidant property of a plant material, the N. latifolia fruits extract showed moderate antioxidant activity for DPPH. The $N$. latifolia fruits extract showed a better antioxidant activity than Origanum onites and $O$. vulgare with $\mathrm{IC}_{50}$ of 395.75 and $335.0 \mu \mathrm{g} / \mathrm{ml}$ respectively (Ozkan and Ozcan, 2016). In the study by Ayeleso et al. (2014), the DPPH radical activity of aqueous extracts of $N$. latifolia fruits and leaves showed an $\mathrm{IC}_{50}$ value of 120 and $20.64 \mathrm{mg} / \mathrm{ml}$ respectively. This indicated that the methanol extract of the plant showed far greater radical scavenging activity compared to the aqueous extract of the plant.
The nitric oxide radical quenching activity of the methanol extract of $N$. latifolia fruits was evaluated and compared with Ascorbic acid as the standard. The nitric oxide scavenging activity wss determined by the ability of the extract to prevent nitrite formation by competing for oxygen, with the nitrogen oxide present in the reaction system. The extract exhibited a concentration dependent quenching activity, the maximum percentage inhibition obtained from the extract was $60.1 \%$ at the highest concentration of $100 \mu \mathrm{g} / \mathrm{ml}$ with $\mathrm{IC}_{50}$ value of $30 \mu \mathrm{g} / \mathrm{ml}$ (Fig. 2). The Ascorbic acid standard however showed a similar concentration dependent trend with a maximum inhibition percentage of $62.5 \%$ at the highest concentration of $100 \mu \mathrm{g} / \mathrm{ml}$ with $I_{50}$ value $<20.0 \mu \mathrm{g} / \mathrm{ml}$. Nitric oxide plays important role in numerous biological processes like vasodilation, antimicrobial and antitumor activities by acting as effector molecules. It is also an active pleotropic mediator for physiological process like neuronal signaling, cell mediated toxicity regulation and platelet aggregation inhibition. It however forms peroxynitrite, a potential cytotoxic molecule, by reacting with superoxide anion under pathological conditions (Kumar and Kumar, 2009). $\alpha$-glucosidase and $\alpha$-amylase activity of $\mathbf{N}$. latifola fruits: The breakdown of starch into oligo- 
saccharides and disaccharides through hydrolysis is mainly carried out in the body by a-amylase. The oligosaccharides and disaccharides produced are subsequently hydrolysed by $\alpha$ glucosidase into monosachharide which is then absorbed into the body through the small intestines resulting in increased postprandial glucose levels (Ranilla et al., 2010).

The inhibitory activities of the methanol extract of $N$. latifolia fruits against $\alpha$-amylase and $\alpha$ glucosidase were evaluated using Acarbose as the control. Figure ( $3 A$ ), shows the inhibitory activity of the extract against $\alpha$-amylase. This indicates a direct proportionality with the concentration, however with a relatively low activity compared to the Acarbose reference sample. At the maximum concentration of $100 \mu \mathrm{g} / \mathrm{ml}$ explored in this research, the percentage inhibition achieved by the plant extract was $23.74 \%$ compared to $83.45 \%$ attained by the reference standard. For its activity against $\alpha$-glucosidase (Fig. 3B), a similar trend was observed for the methanol extract with the percentage inhibition achieved at $100 \mu \mathrm{g} /$ $\mathrm{ml}$ being $38.08 \%$ while Acarbose showed a percentage inhibition of 87.56 at $100 \mu \mathrm{g} / \mathrm{ml}$. Though the extracts showed moderate inhibition activity, a high concentration of the extract will be required to achieve significant inhibition as $50 \%$ inhibitory activity was not achieved by the extract even at $100 \mu \mathrm{g} / \mathrm{ml}$ compared to the standard.

The few a-glucosidase inhibitors that are commercially available contain sugar components and require tedious multistep synthetic procedures. Their use is also usually associated with severe gastrointestinal side effects. Thus, active extracts like those of $N$. latifolia fruits can effectively replace $\alpha$-glucosidase inhibitors like acarbose and voglibose, outwitting their side effects.

\section{Conclusion}

This study has shown that the methanol extract of $N$. latifolia fruit possessed good antioxidant activities as indicated by DPPH, FRAP, TPC and nitric oxide assays. It was, however, observed that with the high phenol content of the extract $(147.9 \pm 3.35$ GAEmg/100g), the antioxidant activity (1604.1 9.20 AAE mg/100g) of the extract should be significantly higher $(P<0.05)$ with the general belief that high phenol content correlates with high antioxidant activity. The inhibitory activity of extract to a-glucosidase and a-amylase was slightly low, but the extract at high concentration could be used in order to avoid the side effects of synthetic inhibitors. With increasing incidence of diabetes in the urban and rural population throughout the world, there is a dire need for the development of indigenous and inexpensive drugs from natural origin for its treatment. This research has provided medicinal justification for the use of $N$. latifolia fruits in the management, control and or treatment of diabetes. Summarily, the high antioxidant values and the moderate inhibition of $\alpha$ glucosidase and $\alpha$-amylase enzymes substantiate the basis of using the plant extract as folkloric remedies for diabetes.

\section{REFERENCES}

1. Abdul, G., Bener, A., Al-Hamaq, A.O. and Yousafzai, M.T. (2014). Relationship between patient satisfactions with diabetes care and treatments. Nigerian Journal of Clinical Practice, 17: 218-225.

2. Agbor, G. A. Oben, J. E. Ngogang, J. Y. Cai X. X. and Vinson, A. J. (2005) "Antioxidant Capacity of Some Herbs/Spices from Cameroon: A Comparative Study of Two Methods," Journal of Agriculture and Food Chemistry, 53 (17): 6819-6824.

3. Ayeleso, A. O., Oguntibeju, O. O. and Brooks, N. L. (2014). In vitro study on the antioxidant potentials of the leaves and fruits of Nauclea latifolia. Sci. World J. http://dx.doi.org/10.115 5/20 14/437081.

4. Benzie, I. and Strain, J. (1999). Ferric reducing/ antioxidant power assay: Direct measure of total antioxidant activity of biological fluids and modified version for simultaneous measurement of total antioxidant power and asorbic acid concentration, Methods in Enzymology 299, 15-27. http:// doi.org/10.1016/s0076-6879(99)99005-5

5. Brewer, M. S. (2011). Natural Antioxidants: Sources, Compounds, Mechanisms of Action, and Potential Applications. Comprehensive Reviews in Food Sciences and Food Safety, 10(4): 221-247.

6. Chung, Y. C. Chang, C. T., Chao, W. W., Lin, C. F. and Chou, S. T. (2002). Antioxidative activity and safety of the 50 ethanolic extract from red bean fermented by Bacillus subtilis IMR-NK1. J. Agri.c Food Chem. 1050(8): 2454-8.

7. Esmaeili, A. K. Taha, R. M. Mohajer, S. and Banisalam, B. (2015) "Antioxidant Activity and Total Phenolic and Flavonoid Content of Various Solvent Extracts from In Vivo and In Vitro Grown Trifolium pratense L. (Red Clover)," Biomed research Interanational. https://doi.org/10.1155/2015/643285.

8. Fadipe, A. L., Haruna, A. K., Mohammad, I. and Pateh, U. U. (2015). Some volatile constituents of the unripe fruits of Nauclea latifolia (Family: Rubiaceae). Journal of Medicinal Plants Studies, 3 (2): 01-04.

9. Green, L. C. Wagner, D. A., Glogowski, J., Skipper, P. L., Wishnok, J. S. and Tannenbaum, S. R. (1982). Analysis of nitrate, nitrite and $15 \mathrm{~N}$ nitrate in biological fluids. Anal. Biochem. 126(1): 131-138.

10.Hadi, S. M., Bhat, S. H., Azmi, A. S., Hanif, S., Shamim, U.and Ullah, M. F. (2007). Oxidative breakage of cellular DNA by plant polyphenols: A putative mechanism for anticancer properties, Semin. Cancer Biol, 17(5): 370-376.

11. Haudecoeura R., Peuchmaura M., Pérèsa B., Romec M., Taïwee G. S., Boumendjela A., and Boucherlea, B. (2018). Traditional uses, phytochemistry and pharmacological properties of African Nauclea species: A review. Journal of Ethnopharmacology 212, 106-136. http://dx.doi.org/10.1016/j.jep.2017.1 0.011.

12.Iwu M. W. (1993). Handbook of African medicinal plants. CRC Press, Boca Raton, Florida.

13.Kim, Y. M., Jeong, Y. K., Wang, M. H., Lee, Y. H. 
and Rhee, H. I. (2005). Inhibitory effect of pine extract on alpha-glucosidase activity and postprandial hyperglycaemia. Nutrition, 21(6): 756-761.

14.Koleva, I. I., van Beek, T. A. Linssen, J. P. H. Groot, A. and Evstatieva, L. N. (2002) Screening of plant extracts for antioxidant activity: a comparative study on three testing methods. Phytochemical analysis, 13 (1); 8-17.

15.Kumar, S. and Kumar, D. (2009). "Antioxidant and free radical scavenging activities of edible weeds". African Journal of Food Agriculture, Nutrition and Development, 9(5): 1174-1190.

16.Labiad, M. H. Harhar, H. Ghanimi, A. and Tabyaoui, M. (2017). Phytochemical Screening and Antioxidant Activity of Moroccan Thymus satureioïdes Extracts. Journal of Materials and Environmental Sciences 8 (6): 2132-2139.

17.Liu, M., Li, X. Q., Weber, C., Lee, C. Y., Brown, J. and Liu, R. H. (2002). Antioxidant and antiproliferation activities of raspberries. Journal of agriculture and food chemistry, 50(10): 2926-2930.

18.Mahdi-Pour, B., Jothy, S. L., Latha, L. Y., Chen, Y. and Sasidharan, S. (2012). Antioxidant activity of methanol extracts of different parts of Lantana camara. Asian Pacific journal of tropical biomedicine, 2 (12), 960-965.

19.Moyo, M., Aremu, A.O. and Van Staden, J., 2015. Medicinal plants: an invaluable, dwindling resource in sub-Saharan Africa. J. Ethnopharmacol. 174, 595606. http://dx.doi.org/10.1016/j.jep.2015.0 4.034.

20.Ozkan, G. and Ozcan M. (2016). Antioxidant activity of some medicinal plant extract on oxidation of olive oil. Food Measurement and Characterization. 11(2): 1-6.

21.Patel, P., Harde, P., Pillai, J., Darji, N. and Patel, B. (2012): Antidiabetic herbal drugs a review. Pharmacophore, 3(1): 18-29.
22.Ranilla, L. G. Kwon, Y. I. Apostolidis, E. and Shetty, K. (2010). Phenolic compounds, antioxidant activity and in vitro inhibitory potential against key enzymes relevant for hyperglycemia and hypertension of commonly used medicinal plants, herbs and spices in Latin America. Bioresour Technol, (12), 4676-4469.

23.Saha, S. Verma, R. (2014) Antioxidant activity of polyphenolic extract of Terminalia chebula Retzius fruits. Journal of Taibah University of Science 10 (6): 1-28.

24.Sen, S., Chakraborty, R., Sridhar, C., Reddy, Y. S. R., and De, B. (2010). Free radicals, antioxidants, diseases and phytomedicines: current status and future prospect. International Journal of Pharmaceutical Sciences Review and Research, 3 (1): 91-100.

25.Shirwaikar, A., Rajendran, K. and Punithaa, I. S. (2006). In vitro antioxidant studies on the benzyl tetra isoquinoline alkaloid berberine. Biological and Pharmaceutical Bulletin, 29(9): 1906-1910.

26.Singh, H. Raturi, R. Sati, M. D. Sati, P. and Badoni, P. (2012). in Chemistry of phytopotentials: Health, Energy and Environmental perspective (Eds.: M. M. Srivastava, L. D. Khemani, S. Srivastava), Springer-Verlag, Berlin Heidelberg, 29-31.

27.Skrovánová, S., Mišurcová, L. and Machů L. (2012). Antioxidant activity and protecting health effects of common medicinal plants. Advances in Food and Nutrition Research, 67, 75-139. http:// dx.doi.org/10.1061/B978-0-12-394598-3.00003-4

28.Xiao Z., Reginald S. and Adrian T. (2006). Quantitative starch-iodine method for measuring alphaamylase and glucoamylase activities. Analytical biochemistry 351(1): 146-148. 